\title{
FOMENTO À INTEGRIDADE: O Compliance como Exigência nas Contratações Públicas
}

\author{
http://dx.doi.org/10.21527/2176-6622.2019.52.267-283
}

Recebido em: 12/3/2019

Modificações requeridas em: 3/6/2019

Aceito em: 17/7/2019

Tomas Julio Ferreira

Mestrando em Direito do Estado e graduado pela Faculdade de Direito da Universidade de São Paulo (Largo São Francisco). Tem experiência na área de Direito, com ênfase em Direito Público (Constitucional e Administrativo). Advogado. http://lattes.cnpq.br/3725822422691153. tomas.julio.ferreira@usp.br

\section{RESUMO}

O presente artigo tem por objetivo analisar criticamente a utilização do poder de compras do Estado como forma de fomento à integridade nas relações entre o setor público e o setor privado, utilizando-se, para tanto, do incentivo à adoção de programas de compliance por parte das empresas. Para tal, são analisadas duas legislações em âmbito estadual nesse sentido, a Lei Estadual (RJ) n. $7.753 / 2017$ e a Lei Distrital n. 6.112/2018, que obrigam as empresas contratantes com a administração pública local a instituírem programas de integridade. Por fim, após um olhar crítico sobre os impactos dessas legislações, propõe-se a utilização de selos de certificação dos programas empresariais de compliance, concedidos por entes públicos ou privados, reconhecidos e especializados nessa atividade, como forma de benefício durante o processo licitatório. A pesquisa desenvolveu-se por meio de uma abordagem dedutiva, relacionando e contrapondo estudos doutrinários dos institutos jurídicos principais, bem como analisando os textos normativos objetos do trabalho.

Palavra-chave: Fomento. Licitações. Poder de compra. Corrupção. Compliance.

\section{PROMOTION OF INTEGRITY: COMPLIANCE AS REQUIREMENT IN PUBLIC CONTRACTS}

\section{ABSTRACT}

The purpose of this article is to critically analyze the use of the Government's purchasing power as a way to promote integrity in the relations between the public and the private sector using, therefore, the incentive for the companies to adopt compliance programs. To that end, we analyze two state-level legislation that were proposed in this sense, the Rio de Janeiro state Law n. $7.753 / 2017$ and Federal District Law n. 6.112/2018, which determine the implementation of compliance programs by companies who are contracting with the local public administration. Finally, after a critical view of the impacts of these laws, we propose to use certification for corporate compliance programs, awarded by public or private entities, recognized and specialized in this activity, as a form of benefit during the bidding process. The research was developed through a deductive approach, relating and contrasting doctrinal studies of the main legal institutes, as well as analyzing the normative texts object of the work.

Keywords: Incentive. Government procurement. Purchasing power. Corruption. Compliance.

\section{SUMÁRIO}

1 Introdução. 2 A Atividade Administrativa de Fomento. 3 O Fomento por Meio do Poder de Compra do Estado. 4 A Lei n. 12.846/2013 e a Instituição e Efetividade dos Programas de Compliance. 5 As Previsões da Lei Estadual (RJ) n. 7.753/2017 e da Lei Distrital n. 6.112/2018. 6 Os Selos de Certificação como Bônus nas Licitações. 7 Conclusão. 8 Referências. 


\section{INTRODUÇÃO}

Atualmente, é muito discutida a possibilidade de utilização das compras governamentais no fomento à integridade entre o setor privado e o setor público. Essa demanda surge em um contexto de crise institucional no Brasil, principalmente após a divulgação de um maciço escândalo de corrupção, envolvendo diversos partidos políticos e demonstrando o desvio de vultosas somas de recursos nos três âmbitos da federação. Trata-se da deflagração da operação anticorrupção "Lava Jato", realizada pela Polícia Federal em conjunto ao Ministério Público Federal, e que, sem dúvidas, tornou-se central para o estudo nacional sobre a temática do compliance.

Somam-se ao histórico desse movimento as pressões internacionais pela edição de uma legislação anticorrupção robusta, nos moldes do norte-americano Foreign Corrupt Practices Act ("FCPA") e do britânico The Bribery Act ("Ukba"), o que levou à edição da Lei Anticorrupção (Lei n. 12.846/2013), que dispõe sobre a responsabilização administrativa e civil de pessoas jurídicas pela prática de atos contra a administração pública, nacional ou estrangeira.

Após a edição dessa lei, ficou reforçado o movimento por maior integridade no relacionamento entre as empresas e o setor público, havendo, no próprio texto legal, o incentivo para a instituição de programas de compliance ${ }^{1}$ por parte das empresas, uma vez que, segundo o artigo 7으, VIII da Lei Anticorrupção, "a existência de mecanismos e procedimentos internos de integridade, auditoria e incentivo à denúncia de irregularidades e a aplicação efetiva de códigos de ética e de conduta no âmbito da pessoa jurídica" (BRASIL, 2013), é um dos fatores a ser considerado na dosimetria da sanção aplicada em decorrência da prática de ato lesivo à administração pública.

Dessa forma, utilizando-se da figura dos programas de integridade, instituída pela Lei Anticorrupção e suas normas relacionadas, o legislador brasileiro buscou usar do poder de compra do Estado, que tem um enorme potencial para fomentar políticas públicas, na criação de uma política de incentivo à integridade empresarial e ao desenvolvimento de mecanismos internos de averiguação e controle de irregularidades.

Assim, diversos projetos de lei ao redor do Brasil estão sendo propostos, em todos os âmbitos da federação, estabelecendo como requisito para contratações públicas, ou mesmo manutenção de contratos públicos já existentes, a criação e manutenção de programas de compliance pelas pessoas jurídicas contratadas. ${ }^{2}$

Esse objetivo de criar um mecanismo de fomento à integridade, por meio do poder de compra do Estado, culminou, até o momento, na promulgação de duas leis estaduais dispondo sobre esse requisto - a Lei Estadual (RJ) n. 7.753/2017 e a Lei Distrital n. 6.112/2018.

Cumpre observar, dessa forma, se ambas as leis são potencialmente efetivas no fomento à integridade e se a forma como está estabelecido o uso do poder de compra do Estado é a mais adequada do ponto de vista teórico. Para tanto, é necessária uma análise geral do que seria essa atividade administrativa de fomento e como ela é empregada por meio do poder de compra do Estado, propondo-se a utilização de quatro critérios para medir sua efetividade.

Após a compreensão desses conceitos, é preciso perpassar brevemente o que são os programas de compliance e como foram incorporadas à legislação brasileira, as normas internacionais e as contribuições doutrinárias sobre o tema. Por fim, o presente trabalho propõe-se a realizar uma análise crítica dos mecanismos já propostos, essencialmente aqueles desenhados pela Lei Estadual (RJ) n. 7.753/2017 e pela Lei Distrital n. 6.112/2018, bem como propor a sugestão de outros potencialmente efetivos.

\footnotetext{
No presente trabalho também entendidos como "programas de integridade"

2 Como, por exemplo: no âmbito federal, o Projeto de Lei n. 7.149/2017; no âmbito estadual, os projetos de lei n. 8/2018 (Tocantins), n. 1.718/2018 (Paraíba), n. 52/2018 (Goiás), n. 335/2017 (Sergipe) e n. 5/2018 (Espírito Santo); e no âmbito municipal, os projetos de lei n. 471/2017 (Rio de Janeiro - RJ), n. 240/2017 (Porto Alegre - RS), n. 295/2017 (Serra - ES), n. 722/2017 (São Paulo - SP), n. 395/2017 (Osasco-SP) e n. 402/2018 (Guarulhos - SP).
} 
Dessa forma, partindo de uma análise essencial de textos doutrinários referenciais para os institutos jurídicos que norteiam a presente pesquisa, serão extraídas as diretrizes metodológicas para análise dos marcos legais sob escrutínio, quais sejam, as leis fluminense e distrital que preveem a exigência do compliance nas contratações públicas. Por isso, a pesquisa desenvolve-se por meio de uma abordagem hipotética-dedutiva, que utiliza como ferramentas uma análise teórica e propositiva de textos doutrinários e legais.

Para tanto, o trabalho estrutura-se em cinco tópicos. No primeiro, são abordados os marcos teóricos que regem a doutrina da atividade administrativa de fomento, procurando compreender um instituto recente e que recebe cada vez mais atenção por sua proximidade com as demandas do Estado contemporâneo. Em seguida, é feito um recorte metodológico do tópico anterior para se compreender o uso da atividade administrativa de fomento por meio do poder de compra do Estado. O terceiro e quarto tópicos abordam e correlacionam, de forma crítica, a Lei Anticorrupção e os marcos legais da exigência do compliance nas contratações com o poder público, a Lei Estadual (RJ) n. 7.753/2017 e a Lei Distrital n. 6.112/2018. Por fim, o trabalho conclui-se com uma alternativa a esse modelo mediante o uso de selos de certificação.

\section{A ATIVIDADE ADMINISTRATIVA DE FOMENTO}

É comum o enfoque doutrinário em duas atividades administrativas, do serviço público e do poder de política, principalmente por já serem definições clássicas e, em certa medida, bem-delimitadas como campo de estudo. Além disso, trata-se de uma conceituação inspirada na divisão dual clássica da doutrina francesa dos albores do século 20 (VALIM, 2015). Já o fomento, por sua vez, é um tema recente do direito administrativo e, embora existente, é pouco estudado pela comunidade jurídica.

Isso decorre de uma visão precipitada de que o fomento, como atividade típica do direito administrativo, é algo historicamente recente, tendo seu desenvolvimento em paralelo com a evolução do Estado intervencionista e provedor do bem-estar social, especialmente no século 20. A interpretação, nesse sentido, pode ter como justificação uma incongruência entre o conceito de fomento e o ideário clássico de Estado liberal, nos moldes previstos pelos seus idealizadores do século 18.

Justamente em confronto com essa conceituação prematura é que De Pozas (1949) conceitua o fomento dentro da estrutura histórica e jurídica da Espanha. O autor demonstra como o conceito latu sensu dessa atividade pode ser encontrado ao longo da história, como no século 16, em que autores espanhóis já descreviam os métodos dos quais o rei se utilizava para que os súditos atuassem de forma conveniente ao interesse público, por intermédio da concessão de títulos honoríficos, por exemplo.

Somente a partir do final do século 19 e no decorrer do 20, no entanto, é que se estrutura formalmente um conceito administrativo do fomento como política fundamental de Estado e essencial às consecuções das finalidades públicas. Para De Pozas (1949), o Estado utiliza-se de quatro medidas para satisfazer as necessidades gerais: a legislação, o poder de polícia, o fomento e o serviço público, sendo estas três últimas as componentes da classificação tricotômica das atividades administrativas. ${ }^{3}$

Uma interessante afirmação do autor é que o poder de polícia seria a modalidade administrativa mais propícia ao Antigo Regime; o fomento seria mais adequado ao Estado liberal e o serviço público seria a atividade preponderante do Estado intervencionista. É feita a ressalva, todavia, de que não se trata de uma excludente, mas, sim, de um predomínio de uma ou outra atividade (DE POZAS, 1949).

Para tanto, De Pozas (1949) diferencia fomento e poder de polícia, expondo que aquele protege e promove enquanto este previne e reprime. Além disso, o instituto não se confundiria com serviço público, posto que, segundo o autor,

\footnotetext{
Para o autor, a legislação pode ou não ser de caráter administrativo, enquanto as outras três atividades sempre são administrativas (DE POZAS, 1949).
} 
(...) com esta modalidade, a administração realiza diretamente e com seus próprios meios o fim perseguido, enquanto que com o fomento ela se limita a estimular os particulares para que esses, por sua própria vontade, desenvolvam uma determinada atividade e cumpram, indiretamente, os fins perseguidos pela administração (p. 46). ${ }^{4}$

Segundo o autor, o fomento se traduziria como “(...) a ação da administração com a finalidade de proteger e promover as atividades, estabelecimentos ou riquezas devidas aos particulares e que satisfazem necessidades públicas ou se estimam de utilidade geral, sem usar da coação, nem criar serviços públicos" (DE POZAS, 1949, p. 46). ${ }^{5}$

Já no contexto brasileiro, a Constituição Federal de 1988, apesar de usar terminologias imprecisas, faz diversas referências à atividade de fomento, utilizando-se de mandamentos como "fomentará", "incentivará", "promoverá", "estimulará", dentre outros. ${ }^{6}$ Assim, verifica-se que a atividade de fomento encontra conformação constitucional, sendo essencial para a consecução planejada e ordenada do interesse público na lógica constitucional e administrativa brasileira.

A própria Carta Constitucional delega ao Estado a função de incentivar a atividade econômica, determinando, conforme previsto em seu artigo 174, que "como agente normativo e regulador da atividade econômica, o Estado exercerá, na forma da lei, as funções de fiscalização, incentivo e planejamento, sendo este determinante para o setor público e indicativo para o setor privado" (BRASIL, 1988).

Partindo da premissa de que o fomento é uma função administrativa, Marques Neto (2015) ensina que o fomento é uma forma de intervenção indireta do Estado na economia, sendo capaz de viabilizar a satisfação de necessidades públicas com mínima restrição da liberdade e da propriedade privada.

Para o autor, há diversos mecanismos que possibilitam a intervenção do Estado na ordem econômica, tais como a sujeição de determinada atividade como serviço público, a regulação de atividades econômicas, o enquadramento de uma atividade como monopólio estatal, a sua prestação por empresas estatais ou, enfim, quando se decide utilizar da figura do fomento (MARQUES NETO, 2015).

Nessa toada, é desenvolvida a ideia de que o fomento seria um verdadeiro instrumento de intervenção estatal na ordem econômica e, enquanto tal, deve ter como principais parâmetros os princípios da subsidiariedade e da proporcionalidade, imprescindíveis para que não ocorra a colisão com valores outros apresentados na Constituição, como o princípio constitucional da livre-iniciativa e o princípio da valorização do trabalho humano (MARQUES NETO, 2015).

Mais recentemente, no entanto, e a partir da prática administrava, observa-se que o fomento não tem uma delimitação teórica tão marcada e fechada como espera parte da doutrina. Passou-se a observar que essa atividade pode estar presente em diversas atuações do Estado, expressando-se em conjunto, muitas das vezes, com outras atividades da administração pública, como a própria prestação de serviços públicos e o exercício do poder de polícia.

A prestação de um serviço público de recapeamento de ruas pode fomentar o desenvolvimento de certa localidade, assim como o uso abusivo e burocrático do poder de polícia na expedição de alvarás para funcionamento comercial pode fomentar a proliferação dos comércios ilegais. Como se observa, o fomento passa a ser observado como algo inerente à lógica de atuação do Estado, inclusive pelo que a literatura norte-americana chama de "fatores comportamentais".

\footnotetext{
4 Tradução livre do original [(...) la Adminstración, con esa modalidad, realiza directamente y con sus propios medios el fin perseguido, mientras que en el fomento se limita a estimular a los particulares pera que sean ellos los que, por su propia voluntad, desarrollando una actividad determinada, cumplan inderectamente el fin que la Administración persigue.]

5 Tradução livre do original [(...) la acción de la Administración encaminada a proteger y promover aquellas actividades, establecimientos o riquezas debidos a los particulares y que satisfacen necesidades públicas o se estiman de utilidad general, sin usar de la coacción ni crear servicios públicos.]

6 O exemplo do disposto no: (i) "Art. 215 da Constituição Federal: Art. 215. O Estado garantirá a todos o pleno exercício dos direitos culturais e acesso às fontes da cultura nacional, e apoiará e incentivará a valorização e a difusão das manifestações culturais"; (ii) "Art. 217. É dever do Estado fomentar práticas desportivas formais e não-formais, como direito de cada um, observados: (...)"; (iii) "Art. 219 (...) Parágrafo único. O Estado estimulará a formação e o fortalecimento da inovação nas empresas, bem como nos demais entes, públicos ou privados, a constituição e a manutenção de parques e polos tecnológicos e de demais ambientes promotores da inovação, a atuação dos inventores independentes e a criação, absorção, difusão e transferência de tecnologia"; e (iv) "Art. 227, §10: § 10 O Estado promoverá programas de assistência integral à saúde da criança, do adolescente e do jovem, admitida a participação de entidades não governamentais, mediante políticas específicas e obedecendo aos seguintes preceitos: (...)" (BRASIL, 1988) [Destaques nossos].
} 
Para autores dessa teoria, não existiria um design neutro para as escolhas, posto que os arquitetos de escolhas (choice architect) podem tentar influenciá-las mediante um nudge (empurrão), de uma maneira que faça a vida das pessoas mais longa, saudável e melhor. Dessa forma, o nudge caracteriza-se como um aspecto da arquitetura de escolhas que altera os comportamentos das pessoas sem proibir nenhuma opção ou mudar significantemente suas iniciativas econômicas. Trata-se, literalmente, de um leve "empurrão". O nudge pode ser usado, assim, para melhorar a vida das pessoas e ajudar a resolver alguns problemas da sociedade, sem limitar a esfera de liberdade dos cidadãos, ou mesmo suas decisões (THALER; SUNSTEIN, 2009).

Cumpre observar, assim, de que forma o poder de compra do Estado pode ser utilizado no fomento a atividades de interesse público. Essa atuação foi pouco destacada pela doutrina mais clássica, uma vez que se tinha uma ideia de que as compras governamentais eram atividades concentradas e fechadas em si, conceito este que está sendo desconstruído por obras mais atuais, principalmente estrangeiras, possibilitando um diálogo destas com o proposto no presente trabalho.

\section{O FOMENTO POR MEIO DO PODER DE COMPRA DO ESTADO}

A forma como devem ser feitas as contratações públicas é muito estudada, analisada e criticada pelos aplicadores do direito, principalmente quando o tema é licitação e contratos administrativos. Historicamente, as compras governamentais são analisadas apenas como meio para se atingir uma finalidade, que é a aquisição de bens e serviços pela administração pública, mas raramente são analisadas como um fim em si mesmo, por exemplo, como forma de contribuir para o desenvolvimento e efetivação de políticas públicas. Tal análise mostra-se essencial, principalmente em razão dos expressivos valores envolvidos.

Isso porque o Estado brasileiro é um grande comprador, movimentando cerca de $13 \%$ do Produto Interno Bruto (PIB) em compras governamentais (BRASIL, 2017). O governo federal, a título de exemplo, realizou sozinho mais de 600 mil compras nos últimos seis anos, totalizando um montante de aproximadamente $R \$$ 300 bilhões de reais em valores históricos (BRASIL, 2018c).

Não se pode deixar de lado o enorme potencial que a movimentação desses recursos tem para fomentar o desenvolvimento nacional e a aplicação de políticas estratégicas delimitadas pelo Estado, independentemente do âmbito da federação.

É claro que os requisitos constitucionais e legais que guiam as compras governamentais devem ser observados, especialmente o princípio da vantajosidade ${ }^{7}$ para a administração pública. Não se propõe, no presente trabalho, a utilização do poder de compras do Estado apenas com a finalidade de fomento, mas, sim, utilizar-se desse potencial com o objetivo de estimular boas práticas de mercado e o desenvolvimento de áreas demandantes, desde que a forma desenhada para utilização do poder de compras tenha impactos materiais relevantes.

O grande dilema, no entanto, é compatibilizar as políticas de fomento por meio das compras governamentais com os princípios que regem a administração pública, em especial os princípios constitucionais da legalidade, impessoalidade, moralidade e eficiência. ${ }^{8}$ Essa necessidade de conjugação está proposta no artigo 3ㅇ da Lei de Licitações e Contratos (Lei n. 8.666/1993), in verbis:

Art. 3o A licitação destina-se a garantir a observância do princípio constitucional da isonomia, a seleção da proposta mais vantajosa para a administração e a promoção do desenvolvimento nacional sustentável e será processada e julgada em estrita conformidade com os princípios básicos da legalidade, da impessoalidade, da moralidade, da igualdade, da publicidade, da probidade administrativa, da vinculação ao instrumento convocatório, do julgamento objetivo e dos que lhes são correlatos (BRASIL, 1993).

\footnotetext{
7 "A maior vantagem apresenta-se quando a administração assumir o dever de realizar a prestação menos onerosa e o particular se obrigar a realizar a melhor e mais completa prestação. Configura-se, portanto, uma relação custo-benefício. A maior vantagem corresponde à situação de menor custo e maior benefício para a Administração" (JUSTEN FILHO, 2008, p. 63).

8 Junto ao princípio da publicidade, são esses os princípios previstos no artigo 37 da Constituição Federal de 1988.
} 
Como se observa, o próprio texto legal trouxe a previsão da "promoção do desenvolvimento nacional sustentável", trecho incluído recentemente por meio da Lei n. 12.349/2010, mas que deve ser aplicado em conformação com os demais princípios e regras do próprio texto legal. Esse dever de fomento ao desenvolvimento pode, por vezes, colidir com o princípio da vantajosidade, uma vez que o uso do poder de compra como forma de viabilização de uma política pública mediante o fomento, pode não resultar na escolha da proposta de menor custo para a administração. Não se deve ignorar, no entanto, o fato de que a adoção dessas políticas pode propiciar um ganho de desenvolvimento a longo prazo de valores incomensuráveis.

A literatura estrangeira há tempos consagra o uso do poder de compra do Estado como forma de propiciar o desenvolvimento tecnológico. Edler e Georghiou (2007), por exemplo, observam como as public procurement (contratações públicas) podem ser um mecanismo efetivo na superação das falhas de mercado, principalmente as assimetrias de informação (information asymmetries) e das falhas de sistema, como as más interações entre os agentes ecônomicos (poor interactions). O Estado seria, assim, um bom articulador e comunicador de preferências e demandas.

Além disso, os autores mostram como as compras governamentais podem ser essenciais à inovação, posto que, por vezes, produtos inovadores apresentam custos iniciais altos e uma grande demanda por parte do Estado pode estimular o seu uso e desenvolver a produção, abaixando custos e acelerando processos inovadores $^{9}$ (EDLER; GEORGHIOU, 2007).

Uyarra e Flanagan (2010) também apontam esse papel do Estado no fomento à inovação, ressaltando, no entanto, que as decisões sobre os "innovation-friendly procurement" (contratações amigáveis à inovação) devem partir da análise caso a caso, levando em considerações objetivos políticos e financeiros.

No Brasil, acompanhando a tendência internacional, a questão da inovação no setor das contratações governamentais vem sendo muito discutida, principalmente após a edição da Lei da Complementar $\mathrm{n}$. 123/2003, também conhecida como a Lei Geral da Micro e Pequena Empresa (MPE), que instituiu um tratamento simplificado, diferenciado e favorecido para as MPEs. Mediante esta lei e suas alterações subsequentes, ficou determinado um procedimento diferenciado para a participação das MPEs nas licitações públicas, conferindo a elas, por exemplo, a preferência em caso de empate. ${ }^{10}$

A consolidação de uma política voltada à inovação foi consubstanciada por meio da Lei n. 10.973/2004, que dispõe sobre incentivos à inovação e à pesquisa científica e tecnológica no ambiente produtivo. Baseada nela, foram editados normativos que modificaram a Lei n. 8.666/93, garantindo um tratamento diferenciado para produtos e serviços que agreguem desenvolvimento e inovação tecnológica.

Apesar de não ser o enfoque do presente trabalho, tais exemplos demonstram como o uso do poder de compra do Estado está sendo cada vez mais utilizado como política pública de fomento, seja às MPEs seja à inovação.

Consolidando todos os aspectos mencionados e para a avaliação da efetividade do uso do poder de compra do Estado como política de fomento, o presente trabalho propõe que seja observada a maior conformidade possível com quatro requisitos, quais sejam: (i) respeito aos princípios constitucionais e legais que norteiam as compras públicas, em especial o princípio da maior vantajosidade; (ii) que o fomento traga o menor custo indireto possível para a administração; (iii) que haja uma intervenção mínima nos negócios dos particulares e (iv) que seja feito um controle de resultados e de efetividade da política.

Partindo dessas premissas, que consubstanciam as considerações a respeito do princípio da proporcionalidade e da subsidiariedade, bem como outros que norteiam as compras governamentais e até mesmo as políticas públicas, como o controle de resultados, por exemplo, busca-se analisar a efetividade de leis que de-

\footnotetext{
"Furthermore, the more radical an innovation, the higher the entry and switching costs. This relates to transaction and learning costs, to adoption of complementary equipment and to lock in and path dependency effects. Those problems of high entry costs are especially virulent in areas in which network effects occur. For products whose value rises with the units sold in the market, there is a high diffusion threshold, especially in ICT areas. The initial purchase of radical innovations is thus hampered. A strong initial demand in an early phase can have accelerating effects. For a variety of reasons, public procurement may remedy those market and system failures and lead to the generation and/or better diffusion of innovations" (EDLER: GEORGHIOU, 2007, p. 956).

${ }^{10}$ Conforme artigo 44 da Lei Complementar n. 123/2006.
} 
terminam a adoção de programas de integridade por parte das empresas que contratem com a administração pública. Para tanto, é necessário uma breve abordagem sobre a figura desses programas e como eles estão previstos no ordenamento pátrio.

\section{A LEI N. 12.846/2013 E A INSTITUIÇÃO E EFETIVIDADE DOS PROGRAMAS DE COMPLIANCE}

Seguindo um movimento internacional que se iniciou na década de 70 do século 20 com o escândalo do Watergate ${ }^{11}$ o Brasil finalmente publicou sua legislação anticorrupção, com responsabilização objetiva das pessoas jurídicas pela prática de atos lesivos à administração pública: a Lei n. 12.846/13.

A pressão internacional, já mencionada anteriormente, advém de uma sucessiva adesão brasileira a tratados internacionais referentes ao combate à corrupção, como a Convenção Interamericana de Combate à Corrupção (1996), no âmbito da Organização dos Estados Americanos (OEA), a Convenção sobre o Combate da Corrupção de Funcionários Públicos Estrangeiros em Transações Comerciais Internacionais (1997), a Organização para a Cooperação e o Desenvolvimento Econômico (OCDE) e a Convenção das Nações Unidas contra a Corrupção (2003), no âmbito da Organização das Nações Unidas (ONU). ${ }^{12}$

Como abordado, a Lei Anticorrupção brasileira trouxe incentivos à adoção, pelas empresas, de mecanismos de compliance. Muitos autores defendem, no entanto, que a forma como está previsto esse incentivo na legislação - apenas como fator de influência no cálculo da multa administrativa ${ }^{13}$ - não é suficiente para motivar as empresas a adotarem medidas simplificadas ou programas de compliance (VERÍSSIMO, 2017).

Tal afirmativa parece proceder, posto que os custos para a instituição desses programas são altos e simulações feitas por pesquisas do mercado mostram que, na maioria das vezes, a ausência do programa de integridade pode ser financeiramente mais interessante para a empresa. Segundo Veríssimo (2017),

O paradoxo, então, é que para ser capaz de realmente motivar as empresas a adotarem o compliance, o Brasil deverá aumentar a probabilidade de que os atos lesivos sejam descobertos, apurados e efetivamente punidos. Atualmente, do ponto de vista das empresas, em termos de análise de custos e benefícios, parece valer a pena apostar na ineficiência do sistema e não implementar o compliance (p. 270).

Apesar, todavia, do esforço internacional e nacional pela instituição de mecanismos anticorrupção, dentre eles os programas de compliance, vale mencionar que uma parte da literatura estrangeira, baseando-se em dados empíricos relativamente concentrados, conclui pela ineficácia desses programas. Por exemplo, Wellner (2005) demonstra como, mesmo nos Estados Unidos, onde a existência de programas efetivos de compliance pode reduzir substancialmente a condenação de uma corporação quando condenada pelos crimes de seus agentes, ou até mesmo ajudar a evitar a acusação - incentivos esses claramente superiores aos do caso brasileiro -, pouquíssimas empresas desenvolvem programas efetivos e, as que assim tentam, têm resultados questionáveis no controle de irregularidades.

Deve ser levado em consideração, entretanto, que esses estudos analisam bases quantitativas muito específicas e restritas ao contexto norte-americano, não significando que a mesma conclusão se aplique ao Brasil. Além disso, a maior parte da doutrina entende que a adoção de programas de integridade ajuda na criação de uma cultura interna das empresas pelo desincentivo à prática de atos ilícitos com o objetivo de aumentar o lucro a qualquer custo (BLOK, 2018). Considera-se que é como se houvesse um posicionamento institucional

\footnotetext{
${ }^{11} \mathrm{Em}$ consequência do escândalo norte-americano do Watergate, que culminou na renúncia do presidente Nixon, o Congresso norteamericano editou o FCPA, iniciando uma pressão global por meio de entidades internacionais, como a OCDE, pela adoção de mecanismos similares por outros países, uma vez que, em decorrência do FCPA, as empresas norte-americanas estavam em desvantagem em relação aos concorrentes internacionais (VERÍSSIMO, 2017).

12 Tais compromissos internacionais foram introduzidos no ordenamento jurídico brasileiro, respectivamente, pelos Decretos n. 4.410/2002, n. $3.678 / 2000$ e n. $5.687 / 2006$.

${ }^{13}$ O Decreto n. 8.420/2015, que regulamenta a Lei Anticorrupção, estabelece em seu artigo 18, inciso V, que do valor da multa administrativa serão subtraídos de "um a quatro por cento do faturamento bruto da pessoa jurídica do último exercício anterior ao da instauração do Processo Administrativo de Responsabilização caso fique comprovado que a pessoa jurídica possui e aplica um programa de integridade, conforme os parâmetros estabelecidos no Capítulo IV" (BRASIL, 2015c).
} 
da empresa e da alta direção de que há uma preferência ao cumprimento estrito das normas, mesmo que seja em detrimento de alguns negócios ou do próprio lucro. Ainda, porém, é baixo o número dos estudos empíricos a respeito do tema no Brasil, estes que serão essenciais para a compreensão da efetividade dos programas no contexto nacional.

Apesar de não ser objetivo do presente trabalho observar a efetividade do incentivo ao compliance na Lei Anticorrupção, é importante mencionar como este foi um passo normativo inicial para o desenvolvimento desses programas pelo empresariado brasileiro; ${ }^{14}$ isto porque a regulamentação da Lei, o Decreto $\mathrm{n}$. 8.420/2015, trouxe os parâmetros gerais para a estruturação de um programa de integridade, definindo, em seu artigo 41, que se trata de um:

(...) conjunto de mecanismos e procedimentos internos de integridade, auditoria e incentivo à denúncia de irregularidades e na aplicação efetiva de códigos de ética e de conduta, políticas e diretrizes com objetivo de detectar e sanar desvios, fraudes, irregularidades e atos ilícitos praticados contra a administração pública, nacional ou estrangeira (BRASIL, 2015c).

O Decreto trouxe, também, no Parágrafo Único do artigo 41, a previsão de que o programa “(...) deve ser estruturado, aplicado e atualizado de acordo com as características e riscos atuais das atividades de cada pessoa jurídica" (BRASIL, 2015c), previsão esta que é essencial, uma vez que não é possível criar normas muito específicas sobre os programas de compliance, principalmente porque tais programas devem ser instituídos pelas empresas adequando-se ao seu tamanho, número de funcionários, setor de atividade, normas a que estão sujeitas, entre outros. Por exemplo, as instituições financeiras devem observar, além da legislação anticorrupção, também as normas de prevenção à lavagem de dinheiro, como a Lei n. 9.613/1998 e os normativos editados pelo Banco Central do Brasil (Bacen). Por tal motivo, normas que tratem sobre os programas de compliance devem trazer apenas conceitos fundamentais, deixando a cargo da pessoa jurídica o desenvolvimento e adequação de seu programa.

Além disso, diversas são as formas de avaliar a efetividade de um programa de compliance, posto que o proposto pelo Decreto n. 8.420/2015 parece incluir a totalidade dos elementos previstos na literatura estrangeira e nas normas internacionais sobre o tema, inclusive abarcando as linhas gerais das disposições previstas nas convenções internacionais das quais o Brasil é signatário (VERÍSSIMO, 2017).

\footnotetext{
${ }^{14}$ Há quem defenda que no âmbito do sistema financeiro a obrigatoriedade de instituição de programas de compliance adveio da Lei de Lavagem de Dinheiro (Lei n. 9.613/1998), da Resolução Bacen n. 2.554/1998 e das Regras de Basileia (BLOK, 2018).
} 
Segundo o artigo 42 do referido decreto, o programa deve ser avaliado de acordo com uma série de requisitos, desde o alto comprometimento da direção da pessoa jurídica até o "monitoramento contínuo do programa de integridade visando seu aperfeiçoamento (...)" (BRASIL, 2015c). ${ }^{15}$ A norma determina, ainda, que, na avaliação dos parâmetros do programa de compliance, sejam considerados o porte e as especificidades da pessoa jurídica. ${ }^{16}$

A norma também estabelece que cabe "ao Ministro de Estado Chefe da Controladoria-Geral da União expedir orientações, normas e procedimentos complementares referentes à avaliação do programa de integridade (...)" (BRASIL, 2015c, artigo 42, §4ㅇ). Isso resultou, por exemplo, na Portaria CGU n. 909/2015, que "dispõe sobre a avaliação de programas de integridade de pessoas jurídicas" (BRASIL, 2015a), bem como a Portaria Conjunta CGU e Secretaria da Micro e Pequena Empresa (SMPE) n. 2.279/2015, que "dispõe sobre a avaliação de programas de integridade de microempresa e de empresa de pequeno porte" (BRASIL, 2015b).

Apesar da grande fonte nacional e estrangeira sobre como construir um bom programa de compliance, inclusive baseado nas convenções internacionais e em normas de padronização, como da International Organization for Standardization (ISO), ${ }^{17}$ o presente artigo tomará como base os requisitos previstos na legislação anticorrupção e nos atos normativos dela decorrentes, principalmente em razão de ser a estrutura mais detalhada sobre o tema no ordenamento brasileiro, bem como pelo fato de ser a utilizada como atenuante da multa administrativa prevista na Lei n. 12.846/2013, além de ser o parâmetro utilizado pelas leis regionais que serão analisadas a seguir.

\section{AS PREVISÕES DA LEI ESTADUAL (RJ) N. 7.753/2017 E DA LEI DISTRITAL N. 6.112/2018}

No afã gerado pela Operação Lava-Jato e pelo fortalecimento da cultura de combate à corrupção no Brasil nos últimos anos, diversas foram as propostas legislativas com o intuito de ampliar a ética nas reações entre os setores público e privado, posto que, ao lado dessas propostas, estão aquelas prevendo a obrigatoriedade de que empresas contratantes com o Poder Público criem e mantenham programas de compliance.

\footnotetext{
${ }^{15} \mathrm{O}$ artigo 42 do Decreto 8.420/2015 elenca como requisitos de avaliação da existência e aplicação do programa de integridade: "I - comprometimento da alta direção da pessoa jurídica, incluídos os conselhos, evidenciado pelo apoio visível e inequívoco ao programa; II - padrões de conduta, código de ética, políticas e procedimentos de integridade, aplicáveis a todos os empregados e administradores, independentemente de cargo ou função exercidos; III - padrões de conduta, código de ética e políticas de integridade estendidas, quando necessário, a terceiros, tais como, fornecedores, prestadores de serviço, agentes intermediários e associados; IV - treinamentos periódicos sobre o programa de integridade; $\mathrm{V}$ - análise periódica de riscos para realizar adaptações necessárias ao programa de integridade; $\mathrm{VI}$ - registros contábeis que reflitam de forma completa e precisa as transações da pessoa jurídica; VII - controles internos que assegurem a pronta elaboração e confiabilidade de relatórios e demonstrações financeiros da pessoa jurídica; VIII - procedimentos específicos para prevenir fraudes e ilícitos no âmbito de processos licitatórios, na execução de contratos administrativos ou em qualquer interação com o setor público, ainda que intermediada por terceiros, tal como pagamento de tributos, sujeição a fiscalizações, ou obtenção de autorizações, licenças, permissões e certidões; IX - independência, estrutura e autoridade da instância interna responsável pela aplicação do programa de integridade e fiscalização de seu cumprimento; $X$ - canais de denúncia de irregularidades, abertos e amplamente divulgados a funcionários e terceiros, e de mecanismos destinados à proteção de denunciantes de boa-fé; XI - medidas disciplinares em caso de violação do programa de integridade; XII - procedimentos que assegurem a pronta interrupção de irregularidades ou infrações detectadas e a tempestiva remediação dos danos gerados; XIII - diligências apropriadas para contratação e, conforme o caso, supervisão, de terceiros, tais como fornecedores, prestadores de serviço, agentes intermediários e associados; XIV - verificação, durante os processos de fusões, aquisições e reestruturações societárias, do cometimento de irregularidades ou ilícitos ou da existência de vulnerabilidades nas pessoas jurídicas envolvidas; XV - monitoramento contínuo do programa de integridade visando seu aperfeiçoamento na prevenção, deteç̧ão e combate à ocorrência dos atos lesivos previstos no artigo 5o da Lei n. 12.846, de 2013; e XVI - transparência da pessoa jurídica quanto a doações para candidatos e partidos políticos" (BRASIL, 2015c).

16 O parágrafo $1^{\text {o do artigo }} 42$ do Decreto n. 8.420/2015 determina que o porte e as especificidades da pessoa jurídica serão analisados tomando por base: "I - a quantidade de funcionários, empregados e colaboradores; II - a complexidade da hierarquia interna e a quantidade de departamentos, diretorias ou setores; III - a utilização de agentes intermediários como consultores ou representantes comerciais; IV - o setor do mercado em que atua; V - os países em que atua, direta ou indiretamente; $\mathrm{VI}$ - o grau de interação com o setor público e a importância de autorizações, licenças e permissões governamentais em suas operações; VII - a quantidade e a localização das pessoas jurídicas que integram o grupo econômico; e VIII - o fato de ser qualificada como microempresa ou empresa de pequeno porte" (BRASIL, 2015c).

17 São exemplos internacionais os acordos já mencionados, dos quais o Brasil é signatário, e as legislações do UKBA e do FCPA. Além disso, também poderiam ser tomadas como parâmetro a ISO 37001:2017 e a ISO 19600:2014. No contexto brasileiro mais recente, até mesmo a recente Lei n. 13.303/2016 traz alguns aspectos de governança e compliance, não de forma tão detalhada quanto a Lei Anticorrupção.
} 
Os motivos para tais propostas vão desde a ineficácia do incentivo proposto à adoção de programas de compliance na Lei Anticorrupção, perpassando o uso do poder de compra do Estado para incentivar o setor privado a adotar esses mecanismos, influenciando todo o mercado a partir das empresas que com ele contratam, até, por fim, a ideia de que o Estado somente pode contratar com empresas éticas, sendo a existência de programas de compliance um critério para tal.

Levando-se em conta um recorte metodológico e a preferência pela análise de leis já aprovadas em âmbito estadual, uma vez que não existe lei semelhante em vigor no âmbito federal, e em razão do maior poder de compra dos Estados em relação aos municípios, serão analisadas as leis dos únicos dois entes regionais da federação que já possuem medidas nesse sentido em vigor: o estado do Rio de Janeiro e o Distrito Federal, com as Leis n. 7.753/2017 e n. 6.112/2018, respectivamente.

Apesar de bastante parecidas, ambas as leis têm suas especificidades, valendo uma breve análise de suas disposições. Pelo artigo 10 da lei fluminense

fica estabelecida a exigência do programa de integridade às empresas que celebrarem contrato, consórcio, convênio, concessão ou parceria público-privado com a administração pública direta, indireta e fundacional do estado do Rio de Janeiro, cujos limites em valor sejam superiores ao da modalidade de licitação por concorrência, sendo $\mathrm{R} \$ 1.500 .000,00$ (um milhão e quinhentos mil reais) para obras e serviços de engenharia $\mathrm{e}$ $\mathrm{R} \$ 650.000,00$ (seiscentos e cinquenta mil reais) para compras e serviços, mesmo que na forma de pregão eletrônico, e o prazo do contrato seja igual ou superior a 180 (cento e oitenta) dias (RIO DE JANEIRO, 2017).

Os critérios para avaliação da efetividade do programa de integridade são os mesmos do disposto no Decreto n. 8.420/2015, já mencionados anteriormente. A única diferença é a substituição do item que trata, na norma federal, da transparência da pessoa jurídica quanto a doações para candidatos e partidos políticos - provavelmente em razão da proibição dessas doações pelo Supremo Tribunal Federal (STF) - e a inclusão do critério que leva em consideração as ações comprovadas de promoção da cultura ética e de integridade por meio de palestras, seminários, workshops, debates e eventos da mesma natureza (artigo 4o, xvi).

Além disso, a norma concede um prazo de 180 dias corridos, a partir da celebração do contrato, para que a pessoa jurídica institua o Programa de Integridade (artigo 5ㅇ). O descumprimento da norma implica aplicação de multa (artigo 6ㅇ), além de acarretar na impossibilidade da contratação da empresa com o Estado do Rio de Janeiro até a regularização da situação (artigo 8ํ).

Um ponto a ser ressaltado na norma é que a comprovação da existência do programa de compliance se dá por meio de uma declaração apresentada pela empresa, cabendo ao gestor, ou fiscal de contrato, no âmbito da administração pública, sem prejuízo de suas demais atividades ordinárias, a tarefa de fiscalizar o estabelecimento do Programa de Integridade, considerando que suas ações não podem, segundo o artigo 11, §2으,

implicar interferência na gestão das empresas nem ingerência de suas competências, devendo ater-se a responsabilidade de aferir o cumprimento do disposto nesta Lei por meio de prova documental emitida pela empresa, comprovando a implantação do programa de integridade (RIO DE JANEIRO, 2017).

A norma autoriza, ainda, em seu artigo 14, "o Poder Executivo estadual a contratar com empresas de consultoria especializadas, objetivando a capacitação de servidores no que tange aos principais aspectos relacionados à identificação de condutas de fraude e corrupção" (RIO DE JANEIRO, 2017).

Já a Lei Distrital n. 6.112/2018 estabelece, em seu artigo 10:

obrigatoriedade de implementação do Programa de Integridade em todas as pessoas jurídicas que celebrem contrato, consórcio, convênio, concessão, parceria público-privada e qualquer outro instrumento ou forma de avença similar, inclusive decorrente de contratação direta ou emergencial, pregão eletrônico e dispensa ou inexigibilidade de licitação, com a administração pública direta ou indireta do Distrito Federal em todas as esferas de poder, com valor global igual ou superior a R\$5.000.000,00 (DISTRITO FEDERAL, 2018).

Conforme previsto no artigo $1, \S 2^{\circ}$, o disposto na norma se aplica "às pessoas jurídicas que firmem relação contratual com prazo de validade ou de execução igual ou superior a 180 dias" (DISTRITO FEDERAL, 2018). Os parâmetros utilizados são muito semelhantes aos da lei fluminense. A grande diferença da lei distrital para sua congênere fluminense, no entanto, é que, enquanto essa exige a comprovação por meio de uma simples 
declaração da empresa, aquela determina, além da declaração, que o programa de integridade seja avaliado por meio da apresentação de relatório de perfil e relatório de conformidade do programa, nos moldes regulados pela Lei n. 12.846/2013 e legislação correlata. ${ }^{18}$

Também fica prevista a aplicação de multa e impossibilidade de contratar com a administração pública distrital em caso de não instauração do programa de integridade ou caso este seja considerado ineficaz (artigos 8 e e 10). A atribuição de verificação da eficácia do programa também é conferida ao órgão ou entidade fiscalizadora do contrato, conforme será definido em ato do chefe do poder respectivo (artigo 13).

Vale ressaltar que existe a possibilidade de que ambas as normas sejam inconstitucionais em razão do entendimento do STF sobre a competência de normas de licitações e contratos editadas por Estados e municípios, posto que caberia à União legislar privativamente sobre normas gerais de licitações, podendo ser entendido que, nesses casos, houve uma invasão da competência da União. ${ }^{19}$

Além disso, o legislador federal, ao editar a Lei Anticorrupção, poderia ter previsto a obrigatoriedade de instituição de programas de integridade por todas as pessoas jurídicas do mercado nacional, mas assim não o fez. Os motivos podem ser os mais variados, como a desproporcionalidade em exigir tais medidas de todas as empresas, sem considerar o porte e o segmento, ou mesmo a falta de mecanismos de verificação e controle, em razão das especificidades dos setores empresariais e das próprias pessoas jurídicas.

Para, todaviam, além da discussão de inconstitucionalidade, que merece uma análise à parte, e apesar do louvável esforço do legislador em buscar uma relação mais íntegra entre o setor privado e o setor público, não parece que a forma escolhida é a melhor para atingir esses objetivos, justamente em razão da ausência dos critérios que foram levantados para a efetivação de uma política de fomento por meio do poder de compra do Estado.

O primeiro critério, do respeito aos princípios constitucionais e legais que norteiam as compras públicas, em especial o princípio da maior vantajosidade, parece ser subtraído em razão da exclusão da possibilidade de contratação pública de todas as empresas que não tenham programas de compliance, o que pode restringir a competitividade do processo licitatório, aumentando o seu custo. Tal princípio somente poderia ser ponderado com o da promoção do desenvolvimento nacional sustentável caso houvesse uma inegável resposta, com comprovações empíricas, de que a instituição de programas de compliance contribui para o desenvolvimento nacional, o que ainda não se verifica.

O segundo critério, de que o fomento por meio das compras públicas traz o menor custo indireto possível para a administração, também não se encontra presente. Para a efetivação da norma, a administração pública terá de capacitar todos os servidores que atuam como fiscais ou gestores de contratos, possibilitando a avaliação da efetividade dos programas de compliance, sem o qual a lei permaneceria "letra morta". Além disso, a lei fluminense, por exemplo, ao prever a possibilidade de contratação de consultorias para realizar treinamento dos servidores do Estado, já deixa explícito o custo indireto que terá de ser desembolsado, situação que não foge do caso do Distrito Federal, considerando que a atribuição dos gestores e fiscais dos contratos é muito semelhante em ambos os casos.

Já o critério da intervenção mínima nos negócios dos particulares também parece prejudicado, pois, apesar de ambas as legislações especificarem que as atividades dos gestores e fiscais não podem implicar interferência ou ingerência na gestão das empresas, ainda é dado um poder muito amplo a esses agentes, podendo ser solicitados documentos internos e não havendo nenhuma disposição sobre a preocupação com

\footnotetext{
${ }^{18}$ A Lei Distrital n. 6.112/2018 foi alterada, em 14/6/2019 pela Lei n. 6.308/2019, que incluiu o artigo 13-A, estabelecendo que o Poder Executivo terá 180 dias para dispor sobre o relatório de perfil da pessoa jurídica e o relatório de conformidade do Programa de Integridade (DISTRITO FEDERAL, 2018).

${ }^{19}$ Ao analisar uma Lei Distrital que impunha restrição à contratação de empresas que realizassem discriminação na mão de obra, a Corte entendeu que "(...) o dispositivo atacado estabelece um critério a ser observado de modo geral nos contratos administrativos do Governo do Distrito Federal, vale dizer, que não especifica tampouco destaca tema capaz de retirar-Ihe a abstração, a generalidade e impessoalidade: também não se trata de norma especial, atinente a particularidades da orientação local - mas, sim, de normal geral de incapacitação para licitar (...)" (BRASIL, 2007). Tal entendimento poderia ser aplicado analogamente ao caso de ambas as leis de integridade, tanto a distrital, quanto a fluminense.
} 
sigilo bancário e empresarial dessas informações. Além disso, o gestor também fica autorizado a colher entrevistas e solicitar novos documentos para a averiguação do programa de integridade, sob pena de aplicação das penalidades previstas nas leis.

Como os critérios legais para averiguação dos programas são muito amplos e gerais, como devem ser, cada empresa desenhará um programa de integridade de acordo com o seu porte, ramo de atividade e número de funcionários, por exemplo. Resta saber até que ponto os gestores e fiscais do contrato terão capacidade de absorver e avaliar essas especificidades. Além disso, vale pontuar que esse aumento da necessidade de contato entre as empresas e os agentes públicos pode propiciar um ambiente mais tendencioso à prática de atos de corrupção.

Por fim, a necessidade de que a política de fomento por meio do poder de compra seja acompanhada de um controle de resultados e de efetividade, também passou despercebida aos olhos do legislador.

O ideal seria a previsão de que a administração manteria um controle para acompanhamento dos impactos da medida, respondendo a questionamentos como: O número de participantes nos processos licitatórios diminuiu? Houve casos de empresas contratadas, que tinham programas de compliance, e praticaram ato de lesivos à administração pública? Foram verificados conflitos entre o setor privado e os agentes públicos em torno dos elementos que trariam efetividade aos programas de compliance? Houve uma diminuição dos casos de corrupção em comparação com Estados e municípios que adotaram a política? Somente assim seria possível averiguar a efetividade de uma política como essa.

A inobservância dessas medidas, que, infelizmente, é o caso das duas legislações estudadas, leva a uma dificuldade teórica e empírica de sustentação da política adotada. O poder de compra do Estado para estimular boas práticas de integridade pode ser usado como uma ferramenta na prevenção a atos ilícitos, no entanto alguns critérios mínimos devem ser observados.

Para além da crítica das medidas já em vigor, cabe também ao presente trabalho propor sugestões de políticas que poderiam ser adotas para se utilizar do poder de compra do Estado no fomento à integridade, sendo, para tanto, essencial a análise das figuras dos selos de certificação.

\section{OS SELOS DE CERTIFICAÇÃO COMO BÔNUS NAS LICITAÇÕES}

Ao se considerar que a exigência da instauração de programas de compliance pelas empresas que forem contratar com a administração, ou manter um contrato já em vigor, carece dos requisitos elencados para uma boa política de fomento por meio do uso do poder de compra do Estado, uma alternativa que pode ser ventilada é a utilização dos selos de certificação, não como requisito para a contratação com o poder público, mas, sim, como um benefício no processo licitatório.

Essas certificações, por si só, já podem ser consideradas fomento, o que se encaixaria, ao apoiar-se na conceituação clássica de De Pozas (1949), no conceito de fomento honorífico, que, por sua vez, compreenderia "as distinções e recompensas que se outorgam com público reconhecimento e proclamação de um ato de conduta exemplar" (p. 52). ${ }^{20}$

Um exemplo desses selos, que trata especificamente da avaliação de programas de compliance, é o fornecido pela Controladoria-Geral da União, em parceria com o Instituto Ethos de Empresas e Responsabilidade Social - o selo "Empresa Pró-Ética". Segundo a apresentação do selo: "A iniciativa consiste em fomentar a adoção voluntária de medidas de integridade pelas empresas, por meio do reconhecimento público daquelas que, independentemente do porte e do ramo de atuação, mostram-se comprometidas em implementar medidas voltadas para a prevenção, detecção e remediação de atos de corrupção e fraude" (BRASIL, 2018a).

Conforme previsto no artigo 13 do Regulamento do selo "Empresa Pró-Ética", a avaliação para fins de recebimento da certificação consiste em um amplo questionário divido em seis áreas: "(i) comprometimento da alta direção e compromisso com a ética; (ii) políticas e procedimentos; (iii) comunicação e treinamento; (iv)

\footnotetext{
${ }^{20}$ Tradução livre do original "Ias distinciones y recompensas que se otorgan con público reconocimiento y proclamación de un acto o de una conducta ejemplar". As outras classificações de fomento, para o autor, seriam os fomentos econômicos e jurídicos (DE POZAS, 1949).
} 
canais de denúncia e remediação; (v) análise de riscos e monitoramento; (vi) transparência e responsabilidade social" (BRASIL, 2018b). Para comprovar as respostas do questionário, as empresas devem anexar os documentos que entenderem necessários, comprovando aderência aos requisitos propostos.

Caso haja necessidade de descaracterizar algum documento, seja para preservar sigilo, pessoal ou comercial, a empresa deve fazê-lo, cuidando para que as partes não tarjadas sejam suficientes para a análise do documento (BRASIL, 2018b).

Além disso, a empresa deve preencher um relatório de análise de perfil, especificando informações como: os setores do mercado em que atua, a extensão da atuação no Brasil e no exterior, o faturamento e a frequência de participação em licitações públicas.

Além disso, segundo o artigo 9o do Regulamento do programa, somente é admitida a avaliação das informações e documentos encaminhados das empresas que cumprem os seguintes requisitos:

(i) não constar do Cadastro de Empresas Inidôneas e Suspensas - CEIS, do Cadastro de Entidades Privadas Sem Fins Lucrativos Impedidas - CEPIM, ou do Cadastro Nacional de Empresas Punidas - CNEP por penalidade aplicada em decorrência de Processo Administrativo de Responsabilização;

(ii) preencher todas as perguntas do questionário de avaliação e apresentar os documentos comprobatórios;

(iii) enviar o questionário de avaliação no prazo estipulado, por meio do Sistema eletrônico do Pró-Ética;

(iv) apresentar as certidões que comprovem a regularidade fiscal no âmbito federal e trabalhista, quais sejam:

a) Certidão de Regularidade Fiscal emitida pela Secretaria da Receita Federal do Brasil (RFB) e pela Procuradoria-Geral da Fazenda Nacional (PGFN);

b) Certificado de Regularidade do FGTS- CRF; e

c) Certidão de Débitos Trabalhistas, emitida pela Justiça do Trabalho;

(v) comprovar ser signatária do Pacto Empresarial pela Integridade e contra a Corrupção, promovido pelo Instituto Ethos de Empresas e Responsabilidade Social;

(vi) não estar participando de negociação para celebração de Acordo de Leniência ou respondendo a Processo Administrativo de Responsabilização de que tratam a Lei n. 12.846/2013 (BRASIL, 2018b).

A exemplo do selo Empresa Pró-Ética, iniciou-se uma movimentação para certificação no Brasil com base na ISO 19600, norma internacional de padronização sobre compliance publicada pela International Organization for Standardization (ISO) e já incorporada ao sistema brasileiro de padronizações pela Associação Brasileira de Normas Técnicas (ABNT). Outras normas da ISO já foram incorporadas à rotina brasileira de certificações, como a conhecida ISO 9001 sobre gestão de qualidade.

Tais certificações, ou outras a serem criadas por instituições sérias e reconhecidas, principalmente governamentais, poderiam ser utilizadas como benefícios nos processos licitatórios, seja por meio do critério de desempate, das margens de preferência, ou mesmo utilizando-se da figura do empate ficto.

Caso o mecanismo escolhido seja o critério de desempate, seria assegurada a preferência às empresas que tenham o selo de reconhecimento de seu programa de integridade. Outro critério que também poderia ser utilizado para fomentar a adoção do compliance pelas empresas é o empate ficto, método adotado pela legislação federal para incentivar o mercado das micro e pequenas empresas por meio do poder de compra do Estado.

Mediante essa figura, em caso de empate, seria dada a possibilidade de a empresa portadora do selo apresentar proposta cobrindo aquela que seria vencedora do certame, uma vez que, nesses casos, o conceito de empate compreenderia as situações em que a apresentação de propostas, pelas empresas portadoras do selo, fossem iguais ou até $10 \%$ maiores que a proposta melhor classificada, caso siga-se o exemplo do empate ficto concedido às micro e pequenas empresas por força da Lei Complementar n. 123/2006. Esse valor percentual pode variar, a depender da vantagem que se deseje conceder à empresa portadora do selo.

Por fim, outro mecanismo possível é o da margem de preferência, esse bem mais delicado, posto que possibilitaria a contratação de uma empresa portadora do selo mesmo que sua proposta fosse inferior ao de outros colocados. Atualmente as margens de preferências estão previstas na Lei n. 8.666/1993 e são utilizadas para estimular produtos e serviços nacionais. 
Por esse mecanismo, a administração teria a faculdade de privilegiar a contratação das empresas portadoras do selo mediante o estabelecimento da margem de preferência, por meio de decreto do Poder Executivo, devendo a margem ser estabelecida com base em estudos revistos periodicamente, em prazo não superior a cinco anos, levando em consideração fatores que verifiquem a efetividade da política, como: (i) métrica de casos de empresas contratadas, que tinham programas de compliance, e praticaram atos lesivos à administração pública; (ii) diminuição dos casos de corrupção em comparação com outros órgãos que não estabeleceram a margem de preferência; (iii) aumento do custo de produtos e serviços; e (iv) análise comparativa de resultados nas revisões dos estudos.

Ademais, esclarece-se que todas as sugestões propostas teriam de ser incorporadas ao ordenamento mediante previsão em lei, em respeito ao princípio da legalidade. Como já proposto, não se ventila no presente trabalho a possibilidade de que os selos sejam utilizados como requisito para contratação, considerando que isso feriria os princípios que envolvem as contratações públicas, conforme posicionamento já manifestado pelo Tribunal de Contas da União (TCU) a respeito de outras certificações:

Afastar os participantes não certificados reduz a possibilidade de alcance da melhor proposta para a Administração, sem que haja justificativa razoável para tanto. Por outro lado, não há óbice para a utilização do aludido certificado para atribuir pontuação à licitante, o que permite reconhecer seu diferencial em relação a outras que não comprovaram a adequação de seu sistema de produção aos critérios de qualidade estabelecidos nas normas pertinentes (BRASIL, 2011).

A proposta do presente trabalho, independentemente do método escolhido para conferir a vantagem à empresa portadora do selo, é que a utilização seja uma faculdade da administração, que poderia, ou não, utilizá-lo como critério editalício.

É certo que, apesar do Selo Empresa Pró-Ética ser uma ótima forma de averiguação da efetividade dos programas de compliance por um órgão especializado na matéria e seguindo os critérios previstos na legislação nacional, ainda teriam de ser realizadas algumas modificações para que a política proposta pelo presente trabalho fosse efetiva.

Uma dessas medidas é o estímulo para que os Estados, por meio de suas controladorias-gerais ou órgãos similares que tenham tais competências, também promovam certificações oficiais de programas de compliance, tomando por base os requisitos previstos da Lei Anticorrupção e das normas correlatas. ${ }^{21}$ Além disso, estes órgãos poderiam credenciar instituições privadas que também concedem certificações, ampliando o número de agentes competentes para realizar as certificações das empresas que assim desejem, sem a necessidade de descentralizar essa competência a todos os gestores e fiscais de contratos da administração.

Em segundo, devem ser adequados aos critérios de certificação para contemplar as micro e pequenas empresas, tomando por base, por exemplo, a Portaria Conjunta CGU/SMPE n. 2.279/2015.

Os benefícios dessa sugestão são inúmeros, destacando-se, por exemplo, o fato de a criação do programa de compliance ocorrer antes da participação no processo licitatório, e não como forma de cumprir um requisto para assinatura do contrato, evitando a existência dos programas pró-forma. Há, também, o fato de os programas de certificação terem prazos de renovação, garantindo uma constante averiguação da efetividade, melhorias e aprofundamento dos mecanismos de integridade instituídos pelas empresas.

Uma das vantagens de maior destaque é o fato de que os selos seriam analisados por servidores de órgãos técnicos especializados em integridade e ética, como a Controladoria-Geral da União, ou agentes privados de empresas de auditoria do setor, não pulverizando a atividade na mão de diversos gestores e fiscais de contratos que, além de suas atividades rotineiras, teriam de averiguar complexos programas de compliance. Além disso, tal medida possibilitaria a melhoria dos próprios processos de avaliação dos programas, criando, também, uma maior unicidade de critérios.

\footnotetext{
${ }^{21}$ É o exemplo do Projeto de Lei n. 2.053/2015, em tramitação na Assembleia Legislativa de Minas Gerais, que cria o Cadastro Mineiro de Empresas Comprometidas com a Ética, a Integridade e sem Corrupção - Cadastro Empresa Minas-Ética. Pela proposta, a certificação seria instituída no âmbito da Controladoria-Geral do Estado e teria como diretriz a Lei Anticorrupção.
} 
É importante, no entanto, que as certificações privadas tenham requisitos sólidos de averiguação das políticas internas para certificação das empresas, seguindo as práticas e orientações dos órgãos de controle e das certificações concedidas por órgãos públicos, como a Controladoria-Geral da União. Isso seria uma forma de dificultar o fim meramente monetário e mercadológico das certificações, apesar de o risco da imagem ser um fator importante para as empresas. O objetivo, sobretudo, é garantir a adequação das práticas internas da empresa com a legislação e garantir uma efetiva mudança na postura e na cultura de seus colaboradores e dirigentes (GOMES; OLIVEIRA, 2017).

Por fim, a proposta ventilada observa os requisitos propostos para uma efetiva política por meio do poder de compra do Estado, e fica assegurado um maior respeito ao princípio da vantajosidade, pois a proposta não inviabilizaria a participação nas compras governamentais daquelas empresas que não têm programas de compliance, estimulando ainda a efetivação do programas por meio de benefícios na licitação, além do fato de que as empresas poderiam utilizar-se do selo para valorizar sua imagem perante o mercado.

Os custos indiretos a serem arcados pela administração são quase nulos, pois os selos seriam concedidos por órgãos e entidades já especializados na concessão de certificações e na análise de questões referentes à integridade e ética. Haveria, também, uma intervenção mínima nos negócios dos particulares, posto que os selos não são obrigatórios e, portanto, adentram a esfera de discricionariedade das empresas, servindo apenas como um incentivo à sua adoção.

Até mesmo a questão da documentação comprobatória demonstra esse lado pouco interventivo na esfera privada, pois no modelo das legislações estaduais os gestores e fiscais podem solicitar documentos das empresas, à medida que, para o recebimento dos selos de certificação, as empresas apresentam espontaneamente os materiais que entendem necessários para comprovação dos programas, e que, se insuficientes, ensejam na negativa da certificação por parte da instituição responsável, não havendo uma intervenção direta nos negócios das empresas.

Por fim, a proposta permite que seja feito um controle de resultados e de efetividade da política, uma vez que, não sendo uma obrigatoriedade à administração pública, mas, sim, uma faculdade a ser inserida como requisito editalício, a administração teria meios de averiguar a efetividade da adoção dos mecanismos e, em caso de resultados negativos, abster-se de utilizar dos critérios de incentivo que foram propostos.

\section{CONCLUSÃO}

Tendo em vista os argumentos mencionados, o presente trabalho buscou analisar como recentemente a doutrina atentou-se para a atividade administrativa de fomento, posto que antes havia uma predominância no estudo do exercício do poder de polícia e na prestação de serviços públicos. O fomento, que na literatura estrangeira já encontrava forte base doutrinária e legislativa, como é o caso espanhol, passou a ser mais explorado no Brasil, principalmente como forma de compreender uma Constituição que traz diversos deveres de fomento ao Estado e até mesmo em razão de uma mudança na lógica de atuação da administração pública, que passou a ser vista como uma parceira da iniciativa privada no incentivo de atividades de interesse público.

Aliado a esse movimento, o poder de compra do Estado também passou a ser reconhecido como um mecanismo importante para o estímulo de políticas públicas, principalmente em razão dos vultosos valores que são movimentados pelas compras governamentais. Se, no entanto, antes as licitações eram vistas precipuamente como um meio de conseguir o menor preço para a administração, atualmente vislumbra-se a possibilidade de flexibilização desse conceito em prol do desenvolvimento nacional sustentável e como forma de estímulo a políticas públicas.

Nesse contexto, verifica-se como o fomento por emprego do poder de compra do Estado necessita do uso de alguns critérios para sua efetividade, e deve ser garantida a observância dos princípios constitucionais e legais que norteiam os processos licitatórios, em especial o princípio da maior vantajosidade à administração pública.

A partir dessas premissas é possível analisar criticamente propostas que desejam incluir como requistos dos processos de licitação, ou para assinatura dos contratos administrativos com o setor público, a instituição de programas de compliance por parte das pessoas jurídicas, e duas leis estaduais nesse sentido já estão em vigor, uma no Rio de Janeiro e outra no Distrito Federal. Tais medidas, entretanto, não encontram a conforma- 
ção com os requisitos apresentados para uma boa política de fomento pelo uso do poder de compra do Estado e, se verificada a ineficiência prática da medida, as leis já em vigor, no Distrito Federal e no Rio de Janeiro, poderiam ser revogadas para que novos mecanismos sejam testados.

Para tanto, uma proposta levantada é a de utilização de selos de certificação dos programas de compliance que são concedidos às empresas, a exemplo do Selo Empresa Pró-Ética, não como requisito da contratação ou assinatura do contrato, mas como um benefício durante o processo licitatório, seja como critério de desempate, ou por meio de figuras como o empate ficto e a margem de preferências, desde que observados requisitos próprios para cada uma dessas políticas.

Tal medida, concedendo uma discricionariedade à administração para utilização ou não dos benefícios em seus editais, possibilitaria uma averiguação da efetividade dos compliance empresarial, pois o tema é relativamente recente no país e a doutrina diverge sobre o potencial desses programas, principalmente em razão das escassas pesquisas empíricas sobre o tema.

O presente trabalho, todavia, toma como premissa o enorme potencial que efetivos programas de compliance têm como forma de prevenir atos ilícitos ou mesmo garantir a formação de uma cultura empresarial que preza pela integridade e pela ética. Para tanto, o poder de compra do Estado pode ser utilizado como uma forma de estimular a adoção desses mecanismos e testar sua efetividade.

Conclui-se que o objetivo precípuo do legislador, na busca por maior lisura nas relações entre agentes públicos e privados, ainda seria mantido. Garantir-se-ia, no entanto, ao mesmo tempo, a observância dos princípios que norteiam as compras governamentais, bem como os requisitos de efetividade para uma boa política pública que se utiliza desse mecanismo.

\section{REFERÊNCIAS}

BLOK, M. Compliance e governança corporativa. 2. ed. Rio de Janeiro: Freitas Bastos, 2018.

BRASIL. Constituição da República Federativa do Brasil de 1988. Diário Oficial da União, Brasília, DF, 5 out. 1988. Disponível em: http://www.planalto.gov.br/ccivil_03/constituicao/constituicaocompilado.htm. Acesso em: 26 nov. 2018.

BRASIL. Controladoria-Geral da União. 2018a. Empresa Pró-Ética. Disponível em: http://www.cgu.gov.br/assuntos/etica-e-integridade/empresa-pro-etica. Acesso em: 1 nov. 2018.

BRASIL. Controladoria-Geral da União. 2018b. Regulamento do Selo Empresa Pró-Ética. Disponível em: http://www.cgu.gov. br/assuntos/etica-e-integridade/empresa-pro-etica/arquivos/documentos-e-manuais/regulamento-pro-etica-2018-2019.pdf. Acesso em: 1으. nov. 2018.

BRASIL. Controladoria-Geral da União. Portaria CGU n. 909, de 7 de abril de 2015. Dispõe sobre a avaliação de programas de integridade de pessoas jurídicas. Diário Oficial da União, Brasília, DF, 8 abr. 2015a. Disponível em: https://www.cgu.gov.br/ sobre/legislacao/arquivos/portarias/portaria_cgu_909_2015.pdf. Acesso em: 27 nov. 2018.

BRASIL. Controladoria-Geral da União. Portaria Conjunta n. 2.279, de 9 de setembro de 2015. Dispõe sobre a avaliação de programas de integridade de microempresa e de empresa de pequeno porte. Diário Oficial da União, Brasília, DF, 10 set. $2015 \mathrm{~b}$. Disponível em: http://www.in.gov.br/materia/-/asset_publisher/Kujrw0TZC2Mb/content/id/30172275/do1-2015-09-10-portaria-conjunta-n-2-279-de-9-de-setembro-de-2015-30172271. Acesso em: 27 nov. 2018.

BRASIL. Decreto n. 8.420, de 18 de março de 2015. Regulamenta a Lei n. 12.846, de 10 de agosto de 2013, que dispõe sobre a responsabilização administrativa de pessoas jurídicas pela prática de atos contra a administração pública, nacional ou estrangeira e dá outras providências. Diário Oficial da União, Brasília, DF, 18 mar. 2015c. Disponível em: http://www.planalto.gov.br/ ccivil_03/_ato2015-2018/2015/decreto/D8420.htm. Acesso em: 29 nov. 2018.

BRASIL. Fundo Nacional de Desenvolvimento da Educação. 2017. Sobre compras governamentais. Disponível em: http://www. fnde.gov.br/acoes/compras-governamentais/sobre-compras-governamentais. Acesso em: 28 nov. 2018.

BRASIL. Lei n. 8.666, de 21 de junho de 1993. Regulamenta o art. 37, inciso XXI, da Constituição Federal, institui normas para licitações e contratos da Administração Pública e dá outras providências. Diário Oficial da União, Brasília, DF, 22 jun. 1993. Disponível em: http://www.planalto.gov.br/ccivil_03/leis//8666cons.htm. Acesso em: 30 nov. 2018.

BRASIL. Lei n. 12.846, de 1ㅇ de agosto de 2013. Dispõe sobre a responsabilização administrativa e civil de pessoas jurídicas pela prática de atos contra a administração pública, nacional ou estrangeira, e dá outras providências. Diário Oficial da União, Brasília, DF, 2 ago. 2013. Disponível em: http://www.planalto.gov.br/ccivil_03/_ato2011-2014/2013/lei/l12846.htm. Acesso em: 30 nov. 2018.

BRASIL. Portal de Compras do Governo Federal. 2018c. Painel de compras do governo. Disponível em: https://www.comprasgovernamentais.gov.br/index.php/painel-de-compras-de-governo. Acesso em: 29 nov. 2018. 
BRASIL. Supremo Tribunal Federal. Ação Direta de Inconstitucionalidade n. 3.679 DF. Plenário. Relator min. Sepúlveda Pertence. Diário da Justiça Eletrônico, Brasília, DF, n. 72, p. 59, 2 ago. 2007.

BRASIL. Tribunal de Contas da União. Acórdão n. 1085/2011. Plenário. Relator min. José Mucio Monteiro. Diário Oficial da União: seção 1, Brasília, DF, n. 85, p. 118, 5 maio 2011.

DE POZAS, L. J. Ensaio de una Teoria del Fomento en el Derecho Administrativo. Revista de Estudios Políticos, Madrid, n. 48, p. 41-54, 1949.

DISTRITO FEDERAL. Lei n. 6.112, de 2 de fevereiro de 2018. Dispõe sobre a obrigatoriedade da implantação do Programa de Integridade nas empresas que contratarem com a Administração Pública do Distrito Federal, em todas esferas de Poder, e dá outras providências. Diário Oficial do Distrito Federal, Distrito Federal, 6 fev. 2018. Disponível em: http://www.sinj.df.gov.br/ sinj/Norma/3bf29283d9ea42ce9b8feff3d4fa253e/Lei_6112_02_02_2018.html. Acesso em: 10 dez. 2018.

DISTRITO FEDERAL. Lei n. 6.308, de 13 de junho de 2019. Altera a Lei n. 6.112, de 2 de fevereiro de 2018, que dispõe sobre a obrigatoriedade da implantação do Programa de Integridade nas empresas que contratarem com a Administração Pública do Distrito Federal, em todas esferas de Poder, e dá outras providências. Diário Oficial do Distrito Federal, Distrito Federal, 14 jun. 2019. Disponível em: http://www.sinj.df.gov.br/sinj/Norma/a451f853649a4ecc8931491b970bc149/Lei_6308_2019.html\#txt_ bc752e56ee514c8528021f910b00029a. Acesso em: 25. jun. 2019.

EDLER, J.; GEORGHIOU, L. Public procurement and innovation: resurrecting the demand side. Research Policy, v. 36, n. 7, p. 949-963, 2007.

GOMES, M. F.; OLIVEIRA, W. R. O. A efetivação do compliance ambiental diante da motivação das certificações brasileiras. Revista de Direito da Faculdade Guanambi, v. 4, n. 1, p. 185-206, jan./jun. 2017.

JUSTEN FILHO, M. Comentários à lei de licitações e contratos administrativos. 12. ed. São Paulo: Dialética, 2008.

MARQUES NETO, F. A. Fomento. In: DI PIETRO, M. S. Z. (coord.). Tratado de direito administrativo. São Paulo: Revista dos Tribunais, 2015. p.404-508. 2 v.

MOREIRA NETO, D. F. Curso de direito administrativo. 16. ed. Rio de Janeiro: Forense, 2014.

RIO DE JANEIRO. Lei no 7753 de 17 de outubro de 2017. Dispõe sobre a instituição do programa de integridade nas empresas que contratarem com a administração pública do Estado do Rio de Janeiro e dá outras providencias. Diário Oficial do Estado do Rio de Janeiro, Rio de Janeiro, RJ, 18 out. 2017. Disponível em: http://alerjln1.alerj.rj.gov.br/CONTLEI.NSF/c8aa0900025feef6032564ec0060dfff/0b110d0140b3d479832581c3005b82ad?OpenDocument\&ExpandSection=-5\%2C-6\#_Section5. Acesso em: 29 nov. 2018.

THALER, R. H.; SUNSTEIN, C. R. Nudge: Improving Decisions About Helth, Wealth, and Happiness. New York: Penguin Books, 2009.

UYARRA, E.; FLANAGAN, K. Understanding the Innovation Impacts of Public Procurement. European Planning Studies, v. 18, n. 1, p. 123-143, 2010.

VALIM, R. A subvenção no Direito Administrativo brasileiro. São Paulo: Contracorrente, 2015.

VERÍSSIMO, C. Compliance: incentivo à adoção de medidas anticorrupção. São Paulo: Saraiva, 2017.

WELLNER, P. A. Effective Compliance Programs and Corporate Criminal Prosecutions. Cardozo Law Review, v. 27, n. 1, p. 497528, 2005. 